\title{
Monitoring the Self-healing of Concrete from the Ultrasonic Pulse Velocity
}

\author{
Letícia A. Camara, Mayara Wons, Ian C.A. Esteves and Ronaldo A. Medeiros-Junior *(D) \\ Department of Civil Construction, Federal University of Parana, Curitiba, PR 81530-000, Brazil; \\ leticiaa.andrade@hotmail.com (L.A.C.); mayara_wons@hotmail.com (M.W.); estevesian3@gmail.com (I.C.A.E.) \\ * Correspondence: medeirosjunior.ufpr@gmail.com; Tel.: +55-41-3361-3440
}

Received: 28 December 2018; Accepted: 31 January 2019; Published: 2 February 2019

\begin{abstract}
Concrete has the ability to naturally heal its cracks, in a process called self-healing. This article aimed to analyze the self-healing of concretes, evaluating the influence of fly ash and the age of occurrence of cracks. Concrete specimens were submitted to cracking at 7 and 28 days. Subsequently, the samples were exposed to 12 wetting and drying cycles in order to favor the self-healing process. The phenomenon was evaluated through the ultrasonic pulse velocity testing, performed weekly on the specimens from the molding stage until the end of all cycles. The concretes showed a decrease in ultrasonic pulse velocity at the time they were cracked. This is due to the greater difficulty in the propagation of ultrasonic waves in the voids formed during cracking. This drop was higher for concrete with fly ash. Also, the results show that the fly ash concretes presented a more expressive self-healing process when cracked at 28 days, which may be related to the presence of pozzolanic reactions and the presence of more anhydrous particles. The concretes without fly ash had self-healing when they were cracked at 7 days. This is explained by the high hydration rate characteristic of ordinary Portland cement.
\end{abstract}

Keywords: self-healing; ultrasonic pulse velocity; fly ash

\section{Introduction}

Cracks in concrete elements favor the entry of aggressive agents and damage the durability of the material. The usual crack repair techniques, such as resin injection, increase the total cost of maintenance [1]. Recent research, however, shows that concrete has an intrinsic property to heal its cracks over time through autogenous self-healing. This process is essentially in the hydration of anhydrous cement particles due to the ingress of water through the cracks. If carbon dioxide penetration is possible, self-healing may also occur through the formation of carbonates [2]. Self-healing can be understood as the ability of a material to close cracks, with little or no external help [3].

In the case of concrete elements, this procedure is feasible through two main ways: autogenous or autonomic self-healing. In the first situation, the recovery of the concrete occurs by a natural process, due to intrinsic properties of the constituents of this material. In the second case, self-healing is stimulated by the addition of special components, which would not naturally form part of the concrete composition [2,4].

Autogenous self-healing can be attributed to two preponderant mechanisms: late hydration of non-hydrated cement particles and carbonation. One of the main solid phases in the concrete hydrated cement paste that can be analyzed by a scanning electron microscope consists of non-hydrated clinker grains. Depending on the particle size distribution of the anhydrous cement and the degree of hydration, these grains can be found in the microstructure of cement pastes even long time after hydration. This is due to the tendency of crystallization of hydration products next to anhydrous clinker particles, in a limited space, which creates a barrier around them [5]. Analyzing the presence 
of water, too, the influence of the ions present in this liquid that will penetrate the cracked concrete is important. Huang et al. [2] compared the efficiency of self-healing in cured cement paste in lime saturated solution, compared to pastes submitted to water. The researchers concluded that calcium favors autogenous self-healing.

The inclusion of fly ash to concrete can enhance self-healing capacity. According to Van Tittelboom et al. [6], the partial substitution of cement by fly ash can contribute to concrete recovery when the mean self-healing mechanism is further hydration. This happens because the inclusion of these materials can reduce hydration rate, keeping non-reacted particles for a longer time. On the other hand, the same is not observed when the preponderant mechanism is carbonation, since pozzolanic reaction consume carbon hydroxide. In addition, the beneficial effect of fly ashes is also reported by Özbay et al. [7] and Termkhajornkit et al. [8] for different mixes, cracking induction methods and post-cracking exposition environments.

The effectiveness of self-healing can be assessed by a series of tests and observations, considering the healing mechanisms involved and cracks arrangement. Van Tittelboom and Bellie [9] classify the techniques used to evaluate the healing efficiency into three groups: visualization and determination tests, regain mechanical properties tests and regain tightness tests. The first group includes obtention and analysis of images, in most of cases by microscopy. That kind of assessment demands the exact determination of cracks location and get more complex when a wide number of cracks is generated in a single specimen. The second group is comprised of strength and stiffness tests. As know that tests are mostly destructive and cannot be repeated to a same specimen. Furthermore, in most of cases the mechanical properties are not fully recovered by self-healing, what makes tightness enhancement the main objective of self-healing cementitious materials. The third class of evaluation is related to tests of permeability, resistance again aggressive solutions diffusion, and bulk continuity. Such as mechanical properties tests, the assessment of permeability and resistance are destructive and not repeatable. The same does not occur in evaluation of continuity by ultrasonic pulse velocity test, as it is a non-destructive method (NDT).

Ultrasonic pulse velocity testing seeks to determine the propagation velocity of longitudinal waves, obtained by ultrasonic pulses, through a concrete component. The principle of the test involves the velocity modifications that the ultrasonic pulse undergoes when it comes into contact with some heterogeneity of the concrete. The heterogeneity can be defined as variation in the proportion of the mixture, internal cracks or deterioration of the concrete [10]. Paths with no heterogeneity are the shortest way to pass the wave, which generates the highest propagation velocity. However, the presence of heterogeneities, such as cracks, causes modifications in the internal structure of the concrete and hinders the passage of the pulse. In the latter case, the travel time is longer than in the first example, reducing the ultrasonic pulse velocity [11].

The test also allows for the evaluation of the effectiveness of the treatment of cracks, as well as the indication of changes of the microstructure properties of the concrete over time, offering parameters in relation to the durability of the structure. Precisely because of presenting these characteristics, the ultrasonic pulse velocity was selected in this study as a potential tool to follow the self-healing process of concretes with different types of cement.

Thus, the main objective of this study is to follow the autogenous self-healing process in concretes produced with different types of cements through the ultrasonic pulse velocity. The influence of fly ash and the age of occurrence of cracks were also evaluated. It is expected that this work can contribute to affirm the efficiency of Ultrasonic Pulse Velocity as an assessment method for self-healing of concrete. Furthermore, the periodic measurements can appoint the self-healing behavior along the concrete age, demonstrating when more attention is required and when tests must be concentrated in related experimental programs. 


\section{Materials and Methods}

Concrete specimens were casted with two types of cements, according to EN 197-1 [12]: (1) Portland cement CEM I $52.5 \mathrm{R}$ and (2) Pozzolanic cement CEM IV/A $32.5 \mathrm{~N}$ (25\% of fly ash in its composition). Therefore, the effect of fly ash on the results was investigated. Table 1 shows the characteristics of the cements.

Table 1. Characteristics of the cements.

\begin{tabular}{|c|c|c|}
\hline Characteristics & CEM I & CEM IV/A \\
\hline Blaine $\left(\mathrm{cm}^{2} / \mathrm{g}\right)$ & 4.430 & 4.183 \\
\hline Initial setting time (h:min) & 03:22 & 04:10 \\
\hline Final setting time (h:min) & 04:05 & 05:00 \\
\hline \# 200 & 0.11 & 0.46 \\
\hline \# 325 & 0.61 & 2.50 \\
\hline Expansibility (mm) & 0.32 & 0.14 \\
\hline Loss on ignition $(\%)$ & 3.53 & 3.29 \\
\hline Insoluble residue (\%) & 0.72 & 25.35 \\
\hline Compressive strength (1 day) & 23.7 & 14.6 \\
\hline Compressive strength ( 3 days) & 38.6 & 27.3 \\
\hline Compressive strength (7 days) & 44.6 & 34.0 \\
\hline Compressive strength (28 days) & 52.5 & 45.1 \\
\hline $\mathrm{Al}_{2} \mathrm{O}_{3}(\%)$ & 4.20 & 9.86 \\
\hline $\mathrm{SiO}_{2}(\%)$ & 18.83 & 29.05 \\
\hline $\mathrm{Fe}_{2} \mathrm{O}_{3}(\%)$ & 2.96 & 4.08 \\
\hline $\mathrm{CaO}(\%)$ & 61.29 & 45.82 \\
\hline $\mathrm{MgO}(\%)$ & 3.64 & 2.64 \\
\hline $\mathrm{SO}_{3}(\%)$ & 3.23 & 2.20 \\
\hline Free $\mathrm{CaO}$ & 0.63 & 0.49 \\
\hline
\end{tabular}

The concrete mixing ratio was defined based on some procedures of IPT/EPUSP design method, that is commonly used in Brazil. First, a binders/aggregate relation is defined, then calculated portions of cement, sand and water are added to a fix amount of gravel until all void spaces get filled. Finally, only water portions are added until the desired slump or the maximum $\mathrm{w} / \mathrm{b}$ relation is obtained. For this experimental program the binders/aggregate relation is $1 / 3.5$ that, according to IPT/EPUSP, grant the production of a high cement content in concrete. That choice aims to provide a greater amount of anhydrate binder particles and calcium hydroxide, favoring self-healing. The water/cement for this study was defined as the necessary content to have a concrete slump equal to $80 \pm 10 \mathrm{~mm}$, that is adequate for casting in great part of structural elements [13]. As a result, the obtained consumptions were: cement $\left(477.4 \mathrm{~kg} / \mathrm{m}^{3}\right)$, fine aggregate $\left(704 \mathrm{~kg} / \mathrm{m}^{3}\right)$, coarse aggregate $\left(1426 \mathrm{~kg} / \mathrm{m}^{3}\right)$ and water to cement ratio $(\mathrm{w} / \mathrm{c}=0.45)$.

Natural sand and granite gravel were used as fine and coarse aggregates, respectively. The sand had specific gravity of $2.66 \mathrm{~g} / \mathrm{cm}^{3}$, bulk density of $1.63 \mathrm{~g} / \mathrm{cm}^{3}$ and water absorption of $0.6 \%$. The gravel had specific gravity of $2.57 \mathrm{~g} / \mathrm{cm}^{3}$, bulk density of $1.51 \mathrm{~g} / \mathrm{cm}^{3}$ and water absorption of $0.8 \%$. No chemical admixtures were used. The coarse aggregate had a maximum aggregate size of $9.5 \mathrm{~mm}$. The selection of this gravel size was based on Akçaoğlu et al. [14]. According to these authors, small aggregates better distribute the stresses inside the concrete, especially in the transition zone, generating more distributed cracking along the material. Therefore, smaller and distributed cracks are formed, which favor the self-healing process of the concrete. Since the intention of the research is to evaluate the self-healing process of concrete over time, and that this recovery could be made inviable with thicker cracks or low cement consumptions, it was decided to favor the self-healing in detriment of the application of usual granulometry and mixing ratios.

Cylindrical test specimens $(\phi 100 \times 200 \mathrm{~mm})$ of concrete were casted, according to NBR 5738 [15]. Concrete specimens were demolded $24 \mathrm{~h}$ after casting and cured in a moist chamber (relative humidity $\geq 95 \%$ and temperature of $23{ }^{\circ} \mathrm{C} \pm 2{ }^{\circ} \mathrm{C}$ ) during 7 or 28 days. 
Two groups of specimens were studied. One of these groups is subjected to cracking (" $\mathrm{C}$ ") and the other not (reference " $\mathrm{R}$ "). In addition, in the cracked group, there is still distinction as to the date of cracking. Some concretes were cracked at 7 days (" $\left.7 C^{\prime \prime}\right)$ after curing and others after 28 days ("28C") after curing. For example, specimen "I28C" means concrete with CEM I cracked at 28 days and IVR means concrete with CEM IV/A and not cracked.

Cracking was induced by applying $80 \%$ of the compressive strength for two minutes. Therefore, the compressive strength of each concrete at 7 and 28 days was determined prior to cracking. Compressive strength test was executed in five specimens per condition, according to NBR 5739 [16] standard. The induction method ( $80 \%$ of the compressive strength) was chosen based on the mechanical characteristics of the concrete presented by ACI 224R-01 [17], which states that the propagation and interconnection of cracks under compression starts from loading with $70 \%$ of the compressive strength. Moreover, Samaha and Hover [18] demonstrate that mass transport is not affected when loads to below $75 \%$ of the concrete maximum loading capacity. When considering total cracks length, Lim et al. [19] noticed an abrupt increase between $70 \%$ and $80 \%$ of concrete strength. By visually analyzing cracking characteristics, Lim et al. [19] observed that it starts from the interfacial transition zone at $70 \%$ of concrete maximum loading capacity and propagates through mortar in a distributed configuration when higher compressive loads are applied. In this experimental program, loading was maintained for $2 \mathrm{~min}$ in order to grant that cracks would not be recovered immediately after unloading.

Subsequent to the cracking induction, all concretes specimens ( $R$ and $C$ ) were exposed to wetting and drying cycles to promote self-healing of the concrete. The exposition by cycles were chosen in order to allow self-healing by further hydration and also by carbonation, in view that water and carbon dioxide are provided in this method. A 7-day cycle was carried out, with $78 \mathrm{~h}$ of immersion in lime saturated solution $(10 \mathrm{~g} / \mathrm{L})$ and $90 \mathrm{~h}$ of drying in the air. The lime saturated solution was used aiming to avoid massive dissolution and loss of alkalis and portlandite. The cycles occurred in a controlled environment with a temperature of $22 \pm 3^{\circ} \mathrm{C}$, relative humidity of $75.4 \pm 6.6 \%$ and carbon dioxide concentration of $0.75 \pm 0.13 \%$. A total of 12 wetting and drying cycles were performed, corresponding to 84 days. Therefore, at the end of the cycles, the 7 day cracked samples (7C) were 91 days old and the 28 days cracked samples (28C) were 112 days old.

Ultrasonic pulse velocity was determined on all specimens before being sent to the moist chamber (after $24 \mathrm{~h}$ of molding) and weekly until the end of the 12 wetting and drying cycles. On the day of cracking induction (7 or 28 days), the test was performed immediately prior to cracking and immediately after cracking. Three specimens per condition were monitored. The tests were always performed with specimens in saturated condition, after the $78 \mathrm{~h}$ of immersion. The ultrasonic pulse velocity was determined according to NBR 8802 [20], equivalent to international standard BS EN 12504-4 [21]. $54 \mathrm{kHz}$ transducers were positioned on the opposite flat faces of the top and base of the specimens.

\section{Results and Discussions}

\subsection{Effect of Time and Fly Ash on Ultrasonic Pulse Velocity}

Figure 1 shows the ultrasonic pulse velocity of the uncracked concrete (R) with CEM I and CEM IV / A ( $25 \%$ of fly ash). These results are the average of 3 specimens and they are used to discuss the effect of time and fly ash on ultrasonic pulse velocity.

According to Figure 1, the ultrasonic pulse velocity increases in the first few hours of the concrete age. This increase is due to the advance of the degree of hydration of the cement, which is more intense in the first hours. The effect of concrete age on the ultrasonic pulse velocity is similar to the effect of age on the compressive strength. At the beginning, the velocity grows faster, and at more advanced ages, this growth is reduced. This result is in agreement with the study of Malhotra and Carino [22]. According to these authors, the growth rate of ultrasonic pulse velocity is similar to the 
rate of compressive strength. However, the ultrasonic pulse velocity normally reaches a threshold value before the final compressive strength.

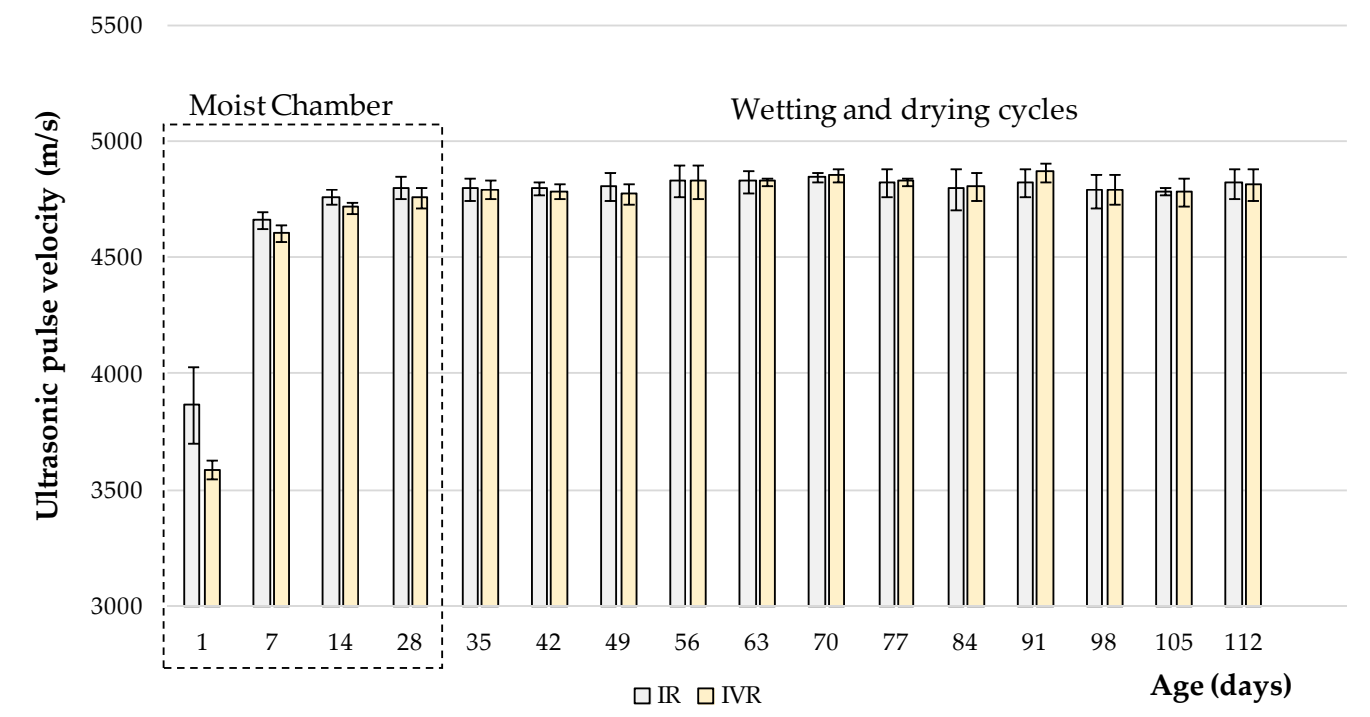

Figure 1. Ultrasonic pulse velocity of the uncracked concrete with CEM I and CEM IV/A.

According to Figure 1, the ultrasonic pulse velocity was higher for the concrete with CEM I, compared to the concrete with fly ash, especially after the first $24 \mathrm{~h}$. The higher ultrasonic pulse velocity of the concrete without fly ash in the early ages can be explained by the high rate of hydration reactions and densification of the concrete matrix with this type of binder in earlier times. The accelerated hydration velocity at the initial ages for concrete with CEM I is attributed to the fineness of this cement (see Table 1), as well as the different dosage of limestone and clay in clinker production, with a higher presence of tricalcium silicate $\left(\mathrm{C}_{3} \mathrm{~S}\right)$. The surface area of the grains represents the material available for hydration, since hydration begins at the surface of the cement particles. In this way, high fineness results in a faster hydration process and higher ultrasonic pulse velocity. Fly ash tends to hydrate more slowly, but these reactions are progressive. So over time, the ultrasonic pulse velocity is similarly independent of the cements (Figure 1).

The results of Figure 1 did not present great variations among cement types from 14 days of age. Therefore, an expressive change in ultrasonic pulse velocity cannot be verified as a function of the cement type at the advanced ages of the concrete. The type of cement influences the ultrasonic velocity mainly in the $24 \mathrm{~h}$ after the concrete molding. The analysis of variance with $95 \%$ significance supports these statements.

In addition, the change in the exposure conditions of the samples-from the moist chamber to the wetting and drying cycles-did not show significant changes in the ultrasonic pulse velocity (from 28 days to 35 days). This can be explained because the ultrasonic pulse velocity readings performed on the specimens during the period of exposure to the wetting and drying cycles were carried out during the wetting periods. Thus, the samples were saturated, as well as when they were inside of the moist chamber, during the first 28 days of age. This result proves that the samples were always saturated during measurements.

\subsection{Effect of Fly Ash on Concrete Self-healing}

Figure 2 shows the ultrasonic pulse velocity (average of 3 specimens) for concrete with CEM I (IR and I28C) and Figure 3 shows the ultrasonic pulse velocity (average of 3 specimens) for concrete with CEM IV / A (IVR and IV28C). The results for the cracked concretes at 7 days will be presented in the sequence. 


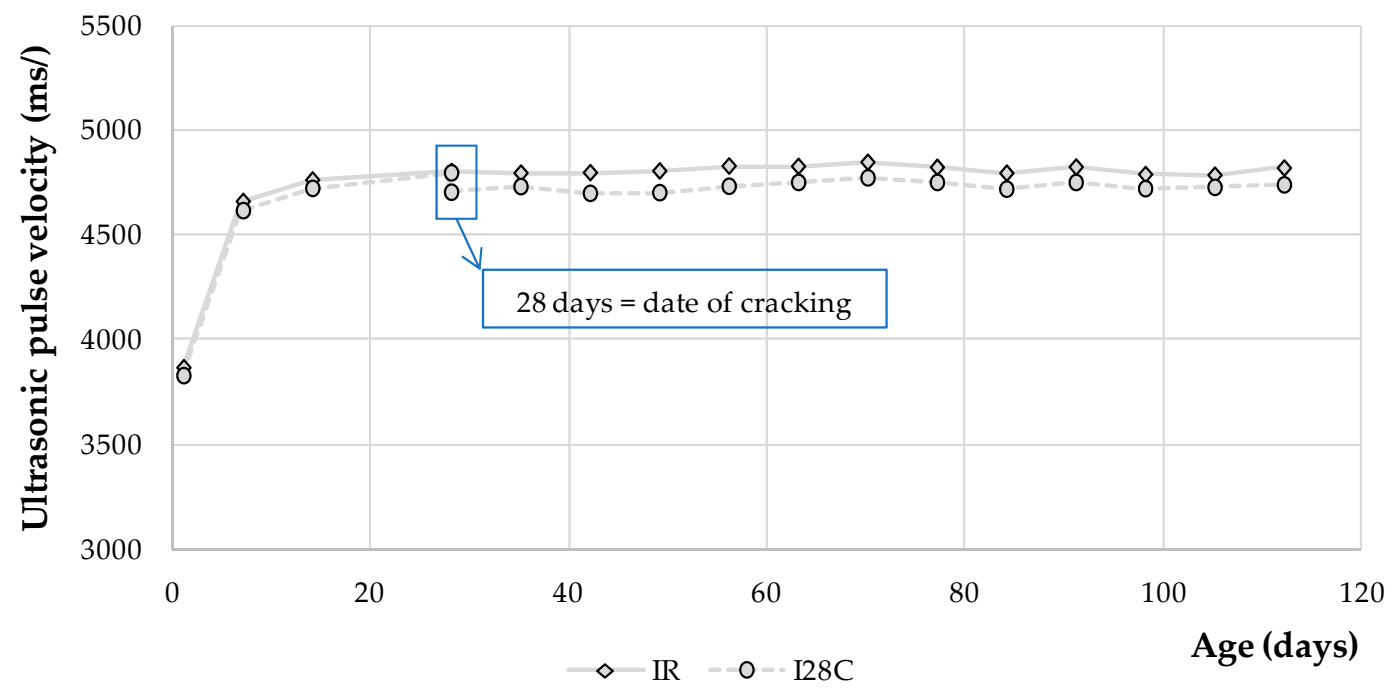

Figure 2. Ultrasonic pulse velocity of uncracked concrete (IR) and 28 day cracked concrete (I28C) with CEM I.

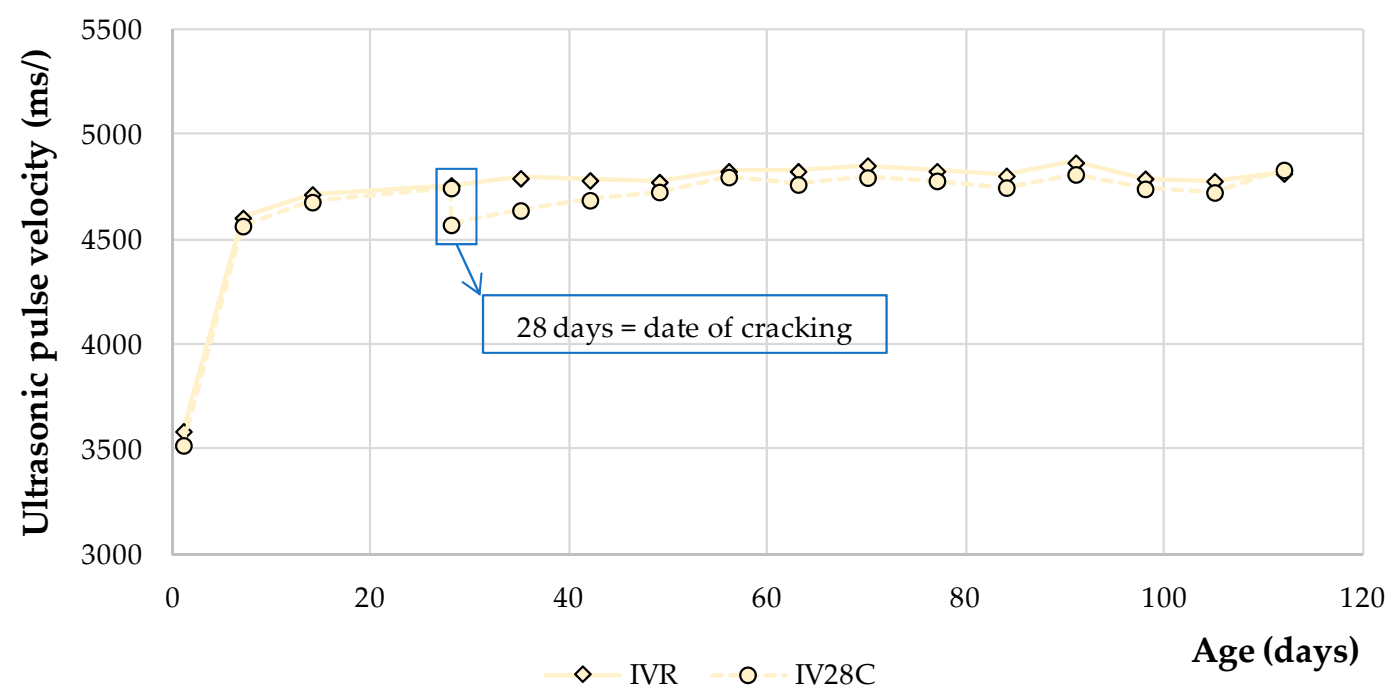

Figure 3. Ultrasonic pulse velocity of uncracked concrete (IVR) and 28 day cracked concrete (IV28C) with CEM IV/A.

According to Figures 2 and 3, the ultrasonic pulse velocity has a drop due to the 28-day cracking induction process. The decrease in ultrasonic velocity after the induction of cracks is related to the effect that the ultrasonic pulse suffers when coming into contact with the discontinuities generated in cracking process. With the opening of cracks, the ultrasonic pulse velocity decreases due to the increased wave travel, resulting from the diffraction of this path around these cracks. In addition, the internal voids generated from cracking also contribute to the difficulty of wave propagation. The reduction in ultrasonic pulse velocity after the cracking process is more evident for concretes with CEM IV / A (3.7\%), when compared to concrete with CEM I (1.9\%). According to Tangpagasit [23], up to 28 days, the strength of cementitious composites containing fly ashes have more contribution of packing effect than pozzolanic effect, what confirms a high presence of unsolved fly ash particles in the mortar. Zhang [24] affirms that there is a weak bond between that particles and the mortar, what favors deviations on linear state of deformation and crack propagation at lower percentages of ultimate strength when compared to composites produced without fly ash.

According to Figure 2, the increase in ultrasonic pulse velocity acquired over the wetting and drying cycles for concrete with CEM I (I28C) was not sufficient to recover the reduction of the ultrasonic 
velocity caused by the cracking induction. This fact is associated with the high hydration rates in the first few days caused by CEM I cement, which results in fewer anhydrous particles capable of reacting at 28 days to form C-S-H crystals and to fill the voids generated.

In relation to the concrete with fly ash (Figure 3), these materials were able to recover the ultrasonic pulse velocity lost in the cracking process (IV28C), reaching the same velocities over the cycles of the concrete that had not been cracked (IVR). Therefore, even with a higher ultrasonic velocity reduction at the time of cracking (3.7\%), concrete with CEM IV/A showed velocity recovery over the 84 days of the wetting and drying cycles, unlike non-pozzolan (CEM I) concrete. These results are in agreement with Van Tittelboom et al. [6] and Sahmaran et al. [25]. Through permeability tests and microscopic observations, respectively, these authors observed that the concretes produced with cement containing pozzolans presented a more efficient behavior for the self-healing process, compared to concretes without any pozzolans. This occurs because pozzolanic reactions from fly ashes take longer to take place when compared to hydration of cement, so at the time of cracking concretes containing fly ash have more unreacted particles what favors formation of hydrated calcium silicates on cracking walls.

The autogenous self-healing process is influenced by the opening of the cracks, which allows the access of external healing agents, such as water and $\mathrm{CO}_{2}$. The presence of water in the concrete contributes to the self-healing process, since the pozzolanic reactions depend on the presence of portlandite and water. In this sense, the greatest increase in ultrasonic pulse velocity for the condition that presented a more expressive decrease of this parameter in the age of cracking follows the expected behavior.

\subsection{Effect of Cracking Induction Age on Concrete Self-healing}

Figures 4 and 5 show the ultrasonic pulse velocity ultrasonic pulse velocity (average of 3 specimens) for cracked concrete at 7 days.

The reduction in ultrasonic pulse velocity for concrete with CEM I was higher for the induction of cracks at 7 days $(2.9 \%)$, compared to the induction of cracks at 28 days $(1.9 \%)$. This event follows the expected, since in smaller ages it is expected that the concrete also has lower hydration rates.

The concrete with CEM I that was cracked at 7 days, despite having presented a superior velocity drop, was able to recover the decrease in ultrasonic pulse velocity along the cycles (Figure 4), unlike that which occurred with the concrete cracked at 28 days (Figure 2). This may be related to the development of hydration of this type of binder, which presents a more accelerated degree in the early ages. Thus, when cracked at 28 days, the concrete produced with CEM I cement probably already had few anhydrous particles that could be hydrated to fill the cracking openings. However, for the induction of cracks at 7 days, the natural process of hydration, still under intense development, may have contributed to the closure of the cracks. Something similar was observed by Zhong and Yao [26]. Analyzing concrete cracking by ultrasonic pulse velocity, these authors noted that the hydration of the High Performance Concrete (HPC) occurs at high rates, reducing the possibility of recovery for cracks generated after the third day.

In addition, the decrease in ultrasonic pulse velocity caused by cracking induction in IC7 concretes is fully recovered in the first wetting and drying cycle, again underscoring the intensity of the hydration process of this type of cement at the early ages. Therefore, the results show that there was self-healing process in IC7 concrete, even without the presence of pozzolanic additions in the concrete composition.

According to Figure 5, the decrease in ultrasonic pulse velocity in the crack induction process was also recovered for the fly ash concrete IVC7. The reestablishment occurred in the first wetting and drying cycle, again being related to the availability of anhydrate particles in the early ages.

It is important to note that the occurrence of cracking was inferred by the reduction in the ultrasonic pulse velocity and the cracked concrete groups variation coefficients are maximum $2 \%$. The cracking induction method used here generates cracks predominantly internal to the concrete and distributed throughout the specimen. There was no possibility of a visual analysis of the cracks and their sealing, since the specimens would be compromised, and the readings of the ultrasound 
pulse velocity would not be continued. Therefore, the authors recommend future studies containing ultrasonic test and image analysis in parallel, with more specimens and using a cracking method that would allow standardization and identification of the exact location of the cracks, such as those applied by Gupta and Biparva [27] and El-Newihy et al. [28].

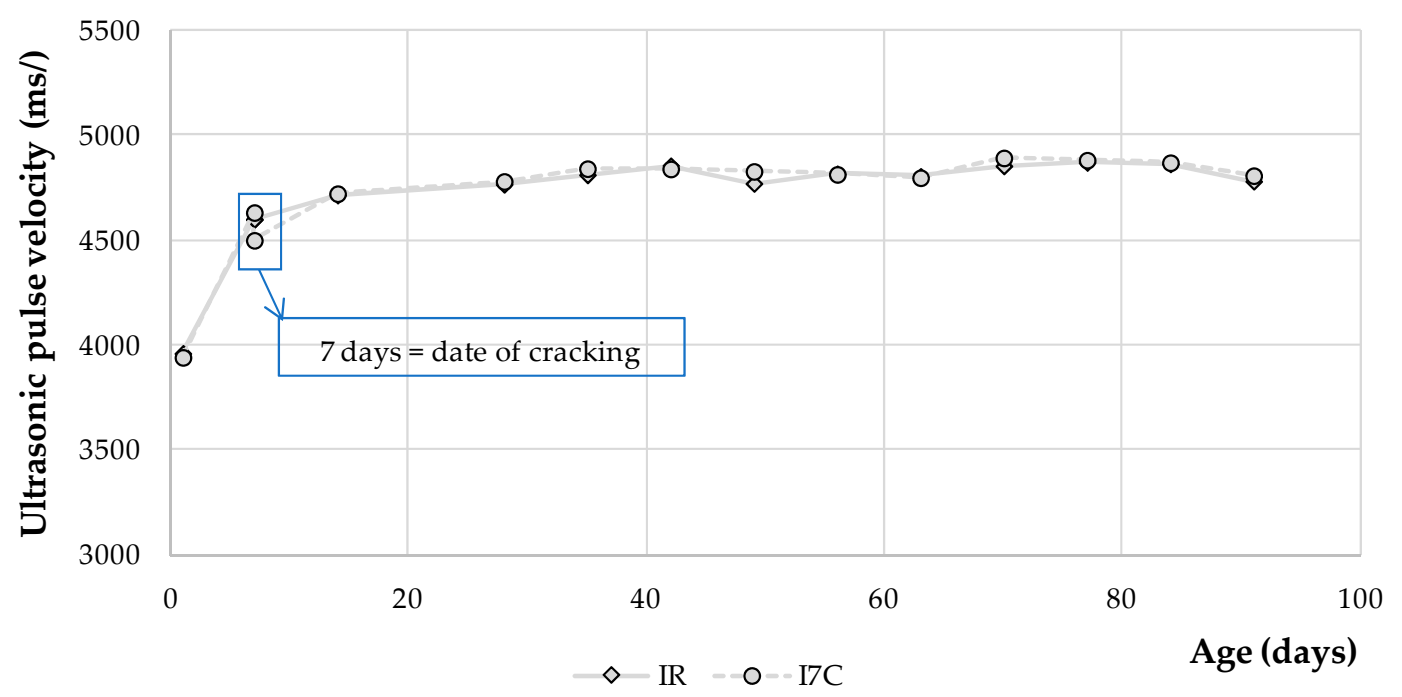

Figure 4. Ultrasonic pulse velocity of uncracked concrete (IR) and 7 day cracked concrete (I7C) with CEM I.

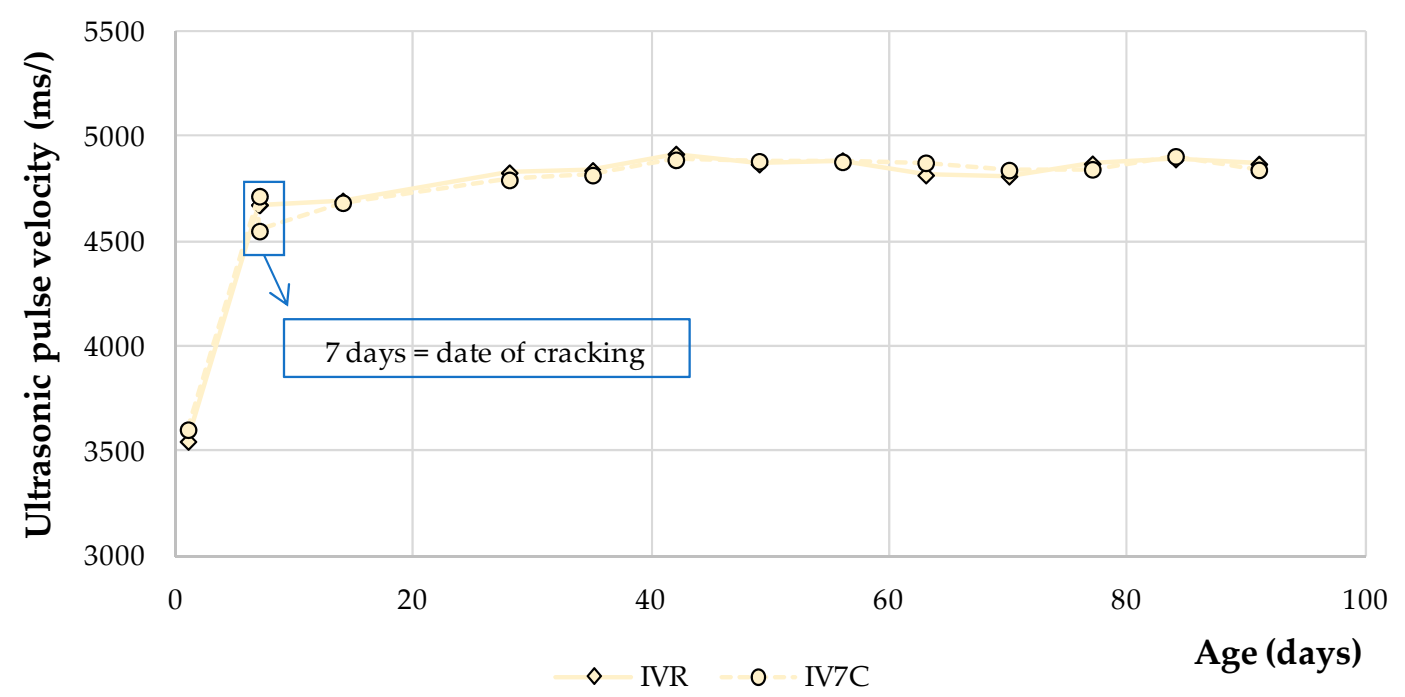

Figure 5. Ultrasonic pulse velocity of uncracked concrete (IVR) and 7 day cracked concrete (IV7C) with CEM IV / A.

\section{Conclusions}

When cracking is not considered, the effect of fly ash presence on reducing the ultrasonic pulse velocity is relevant only within the first days after the concrete is produced. From the 14 days of age, no significant differences were found between the concretes made with the different types of cement.

Greater reduction of ultrasonic velocity after the 28-day cracking process was identified for fly ash cement, when compared with CEM I. Comparing the same type of cement, the decrease in ultrasonic pulse velocity is greater when the cracks are applied at 7 days, compared to 28 days.

Concrete with CEM I cement fissured at 28 days cannot recover ultrasonic pulse velocity, indicating little self-healing process. However, the cracked concretes at 7 days were able to completely recover the ultrasonic pulse velocity after the first wetting and drying cycle, although the ultrasonic velocity 
drop was higher in this case. This is related to the accelerated development of hydration of ordinary Portland cement in the early ages, which decreases the supply of anhydrous particles that can be hydrated at later ages ( 28 days).

Concrete with cement CEM IV/A fissured at 7 and 28 days can recover the ultrasonic pulse velocity, indicating high intensity of self-healing process. This is associated with the presence of fly ash, since the pozzolanic additions provide larger amounts of particles that have not yet reacted at more advanced ages. In addition, pozzolanic reactions contribute to this process. Thus, in the present article, it was verified that the concrete self-healing was more evident in the samples containing cements with fly ash, when analyzed through the ultrasonic test.

For future studies, it is recommended to carry out research with larger groups of samples and ages of cracking, in order to investigate the influence of the induction process on concrete self-healing. It is also suggested that other studies be carried out using cements with different types of mineral additions, in order to evaluate which additions are most beneficial to the self-healing process, analyzed by ultrasonic tests.

Author Contributions: Conceptualization, I.C.A.E. and R.A.M.-J.; Methodology, L.A.C. and M.W.; Formal analysis, L.A.C., M.W., I.C.A.E. and R.A.M.-J.; Writing—original draft preparation, R.A.M.-J.

Funding: This research received no external funding.

Acknowledgments: The authors wish to express their gratitude to the Post-Graduation Program in Civil Construction (PPGECC) of the Federal University of Parana (UFPR), the "Coordenação de Aperfeiçoamento de Pessoal de Nível Superior (CAPES)" and the "Conselho Nacional de Desenvolvimento Científico e Tecnológico (CNPq)".

Conflicts of Interest: The authors declare no conflict of interest.

\section{References}

1. Takagi, E.M.; Lima, M.G.; Helene, P.; Medeiros-Junior, R.A. Self-healing of self-compacting concretes made with blast furnace slag cements activated by crystalline admixture. Int. J. Mater. Prod. Technol. 2018, 56, 169-186. [CrossRef]

2. Huang, H.; Ye, G.; Qian, C.; Schlangen, E. Self-healing in cementitious materials: Materials, methods and service conditions. Mater. Des. 2016, 92, 499-511. [CrossRef]

3. Roig-Flores, M.; Moscato, S.; Serna, P.; Ferrara, L. Self-healing capability of concrete with crystalline admixtures in different environments. Constr. Build. Mater. 2015, 86, 1-11. [CrossRef]

4. Souza, D.J.; Yamashita, L.Y.; Dranka, F.; Medeiros, M.H.F.; Medeiros-Junior, R.A. Repair Mortars Incorporating Multiwalled Carbon Nanotubes: Shrinkage and Sodium Sulfate Attack. J. Mater. Civ. Eng. 2017, 29, 04017246. [CrossRef]

5. Mehta, P.K.; Monteiro, P.J.M. Concrete: Structures, Properties and Materials, 4th ed.; McGraw-Hill: New York, NY, USA, 2013; pp. 5-645.

6. Van Tittelboom, K.; Gruyaert, E.; Rahier, H.; De Belie, N. Influence of mix composition on the extent of autogenous crack healing by continued hydration or calcium carbonate formation. Constr. Build. Mater. 2012, 37, 349-359. [CrossRef]

7. Özbay, E.; Sahmaran, M.; Lachemi, M.; Yücel, H.E. Self-healing of microcracks in high-volume fly-ash incorporated engineered cementitious composites. ACI Mater. J. 2013, 110, 33-43.

8. Termkhajornkit, P.; Nawa, T.; Yamashiro, Y.; Saito, T. Self-healing ability of fly ash-cement systems. Cem. Concr. Compos. 2009, 31, 195-203. [CrossRef]

9. Van Tittelboom, K.; Bellie, N. Self-Healing in Cementitious Materials-A Review. Materials 2013, 6, 2182-2217. [CrossRef] [PubMed]

10. ACI 228.2R. Report on Nondestructive Test Methods for Evaluation of Concrete; American Concrete Institute: Farmington Hills, MI, USA, 2013.

11. Esteves, I.C.A.; Medeiros-Junior, R.A.; Medeiros, M.H.F. NDT for bridges durability assessment on urban-industrial environment in Brazil. Int. J. Build. Pathol. Adapt. 2018, 36, 500-515. [CrossRef]

12. EN 197-1. Cement-Part 1: Composition, Specifications and Conformity Criteria for Common Cements; Norme Européenne: Brussels, Belgium, 2000. 
13. NBR 6118. Design of Structural Concrete-Procedure (in Portuguese: Projeto de Estrutura de Concreto-Procedimento); Brazilian Association of Technical Standards: Rio de Janeiro, Brazil, 2014.

14. Akçaoğlu, T. Determining aggregate size \& shape effect on concrete microcracking under compression by means of a degree of reversibility method. Constr. Build. Mater. 2017, 143, 376-386. [CrossRef]

15. NBR 5738. Concrete-Procedure for Casting and Curing of Test Specimens (in Portuguese: Concreto_Procedimento Para Moldagem e Cura de Corpos de Prova); Brazilian Association of Technical Standards: Rio de Janeiro, Brazil, 2016.

16. NBR 5739. Concrete-Compression Tests of Cylindrical Specimens (in Portuguese: Concreto-Ensaios de Compressão de Corpos-de-Prova Cilindricos); Brazilian Association of Technical Standards: Rio de Janeiro, Brazil, 2007.

17. ACI 224R-01. Control of Cracking in Concrete Structures; American Concrete Institute: Farmington Hills, MI, USA, 2008.

18. Samaha, H.R.; Hover, K.C. Influence of microcracking on the mass transport properties of concrete. $A C I$ Mater. J. 1992, 89, 416-424.

19. Lim, C.C.; Gowripalan, N.; Sirivivatnanon, V. Microcracking and chloride permeability of concrete under uniaxial compression. Cem. Concr. Compos. 2000, 22, 353-360. [CrossRef]

20. NBR 8802. Concrete-Determination of Ultrasonic Pulse Velocity (in Portuguese: Concreto Endurecido-Determinação da Velocidade de Propagação de Onda Ultrassônica; Brazilian Association of Technical Standards: Rio de Janeiro, Brazil, 2013.

21. BS EN 12504-4. Determination of Ultrasonic Pulse Velocity; British Standards Institution: London, UK, 2004.

22. Malhota, V.M.; Carino, N.J. Handbook on Nondestructive Testing of Concrete, 2nd ed.; CRC Press: Boca Raton, FL, USA, 2004; pp. 50-200.

23. Tangpagasit, J.; Cheerarot, R.; Jaturapitakkul, C.; Kiattikomol, K. Packing effect and pozzolanic reaction of fly ash in mortar. Cem. Concr. Res. 2005, 35, 1145-1151. [CrossRef]

24. Zhang, M.H. Microstructure, crack propagation and mechanical properties of cement pastes containing high volumes of fly ashes. Cem. Concr. Res. 1995, 25, 1165-1178. [CrossRef]

25. Sahmaran, M.; Yildirim, G.; Erdem, T.K. Self-healing capability of cementitious composites incorporating different supplementary cementitious materials. Cem. Concr. Compos. 2013, 35, 89-101. [CrossRef]

26. Zhong, W.; Yao, W. Influence of damage degree on self-healing of concrete. Constr. Build. Mater. 2008, 22, 1137-1142. [CrossRef]

27. Gupta, R.; Biparva, A. Innovative Test Technique to Evaluate "Self-Sealing" of Concrete. J. Test. Eval. 2014, 43, 1091-1098. [CrossRef]

28. El-Newihy, A.; Azarsa, P.; Gupta, R.; Biparva, A. Effect of Polypropylene Fibers on Self-Healing and Dynamic Modulus of Elasticity Recovery of Fiber Reinforced Concrete. Fibers 2018, 6, 9. [CrossRef] 